\title{
School Governance, Accountability and Performance Management
}

\author{
Daniela M. Salvioni ${ }^{1} \&$ Raffaella Cassano $^{1}$ \\ ${ }^{1}$ Department of Economics and Management, University of Brescia, Italy \\ Correspondence: Raffaella Cassano, Department of Economics and Management, University of Brescia, Italy. \\ Received: March 16, 2017 \\ Accepted: April 5, 2017 \\ Online Published: April 20, 2017 \\ doi:10.5430/ijfr.v8n2p176 \\ URL: https://doi.org/10.5430/ijfr.v8n2p176
}

Author Contributions: The authors conceived and shared the research work, from which it results this manuscript. Daniela M. Salvioni wrote Sections 1 and 4; Raffaella Cassano wrote Sections 2 and 3.

\begin{abstract}
Limited resources, recent reforms of educational system that impose rapid changes in the governance system, high demand for managerial skill and operational autonomy, impose the capability to optimize performance, transparency of behaviour, dialogue with stakeholder to grow results in the school system. It therefore draws attention to the importance of activate long-term positive relations between schools, students, families, governmental authority and other structures of public Administration to improve quality and performance in school management. So is critical an effectiveness accountability system as starting point to develop the quality of relations between the schools and their stakeholders. In this regard, this article proposes the Network Governance as lever to improve an effectiveness stakeholder engagement and to optimize performance in the School System. This study represents a dissertation that aims to raise awareness about the cycle of performance management in schools and for the optimization of the use of public resources.
\end{abstract}

Keywords: school governance, transparency, accountability, network governance

\section{Introduction}

The effectiveness of the school system has always been a central issue in the reform plans of all European countries in relation to the development objectives for intelligent, sustainable and inclusive enclosed in European Strategy 2020, supported by the European Union.

In this context are taking ever greater consideration: the relation between school-territory to promote a high quality of education in an inclusive approach and equal opportunities; the alternation school-work oriented to lifelong learning and the development of employment; the reorganization of the educational systems according to autonomy, effectiveness and efficiency; enhancement of the role of all stakeholders materializing the concept of global citizenship; the right to study in the system of higher education and the internationalization of the whole system of higher education; the digital innovation of national educational system; the requalification of the built heritage devoted to education [Boeve-De-Pauw, Gericke, Olsson, Berglund, 2015].

In the process of change in act, the consolidation of the school autonomy and the national system of evaluation represents the essential condition to ensure the governance structures stable and effective, able to optimize the use of the organic and constitute an integrated system of training and education for the entire cycle of formation [Franzoni \& Gennari, 2013].

The autonomy is an essential condition also to orient skillful and competent leaders with a high educational culture and, at the same time, remarkable managerial skills.

Actually, the acknowledgement of schools autonomy started to spread in European countries since 1980 and it significantly developed in the United Kingdom (Education Reform Act 1988), Finland, Netherlands and in Sweden.

The educational system reorganization is connected to the growing need of the spending review, which has led the political system to ask administrative boards for costs, use of resources and results evaluation reduction [Folke, Carpenter, Elmqvist, Gunderson, Holling, Walker, 2002]. The transformation of institutional structures of educational systems are based on the principles of vertical and horizontal subsidiarity and managerial autonomy. 
The normative reforms have introduced new paradigms and new tools to make concrete the autonomy of the schools. Specifically arise new critical aspects:

- reduced dependency by the institutional protection ensured by central or local administrative systems (prevision of school autonomy, educational and organizational in law);

- development of significant personal relations with relevant actors and management skills needed for an effective governance;

- increasing the sense of responsibility about contents and methods (What are the school responsibilities? Which government bodies assume these responsibilities with respect to third parties? To whom, for what reasons and with which means school should interact with their stakeholder?)

A recent European scientific research on "School Governance to Build a Learning Community" has highlighted that the implementation of the regulation still has difficulties on the part of the individual schools because of the obvious lack of basic management skills. In particular it is perceived the importance of the development of the educational process and evaluation systems aimed at the activation of the process of learning and of constant improvement in the quality of the school system is in reality perceived, but the skills and tools are often not available for its implementation [Franzoni \& Gennari, 2013; Salvioni, Gandini, Franzoni, Gennari, 2012].

\section{The Cycle of Performance Management of the Educational System}

The school autonomy, introduced through reforms, enlarges the school responsibility area and makes the need of accountability significant.

The present study wants to open a discussion on the best accountability model that determines the connection between school autonomy and responsibility according to the following priority tasks:

- fulfill stakeholders' need of knowing the public value created and provide transparency on the way school decisions are taken;

- improve a governance oriented to active citizenship through the inter-institutional coordination of local development policies;

- create the reputational conditions to ensure a major economical stakeholders' participation;

- strengthen quality management and institute self-evaluation, acknowledging in accountability the conclusive step of management cycle of school performance.

Accountability is the result of an interaction between process and reporting tools aiming at informing the stakeholders and managing the relations with the latters underlining with transparency their responsibilities. In particular, the effective fulfillment of stakeholders' expectations is linked to the school ability to manage, in an integrated way, its economic and socio-environmental responsibility [Salvioni \& Cassano, 2015].

Therefore, the reporting process, intended as method, requires the consideration of ethical values and principles at the base of responsibility such as transparency, comparability, inclusiveness, accuracy, completeness, clarity, neutrality and effectiveness [Cassano, 2013].

The adoption of an integrated concept of responsibility focused on effective relations with stakeholders, emphasizes the importance of school communication. Actually, the compulsory school assumes particular importance because it is a compulsory educational path for all citizens and its quality is essential for the education of future human capital.

The contribution given by the compulsory school in favour of a smart, sustainable, inclusive growth, leads to reflect on the incompleteness of an accountability model only focused on social dimension, given the close interrelationship between social function and ability of effective and efficient use of limited available financial resources [Paletta, 2007; Salvioni \& Astori, 2013; Burton \& Dunn, 2005].

In this context, characterized by the presence of three categories of main actors (government body, service end user and service supplier), the substantial pursuit of informative mutual and constructive exchange among social partners, at the base of managerial autonomy, starts from the analysis of models of relations management which are associated to the reference context.

School governance with a limited propensity towards social responsibility and sustainability, primarily focused on environmental issues or the simple introduction of sustainability issues into existing programs cannot be considered an efficient and exhaustive condition to promote change and above all to ensure the optimization of value creation (economic, social and environmental) for stakeholders [Rowe, 2007; Salvioni, Astori \& Cassano, 2014; Mitchell, 
Van Buren, Greenwood \& Freeman, 2015].

Indeed, stakeholder value creation assumes particular importance in school as a factor qualifying their image, acquiring consensus, trust and resources. Such behaviour presupposes embracing policies aimed at emphasizing the principles of social responsibility, the internal dissemination of the culture of such responsibility and a clear focus on economic and social-environmental performance.

Governance policy relates to the vision, mission, purpose and main objectives of a school. Transforming the policy into actual results entails disseminating all the behaviors of a sustainability culture and implementing appropriate systems of direct accountability to both internal and external stakeholders [Crow, 2010; Salvioni, 2005].

The institutionalization of the principle of sustainability is only achieved when accepted and integrated in the school governance culture and progressively becomes part of the activities implemented. In other words, the governance approach of schools oriented to social responsibility is aimed at enhancing the close interdependence between economic and social efficiency, optimizing performance along the triple bottom line and involving all the management processes. A partial vision of the theme does not lead to real change and a holistic approach to sustainable development in the school system (Figure 1).

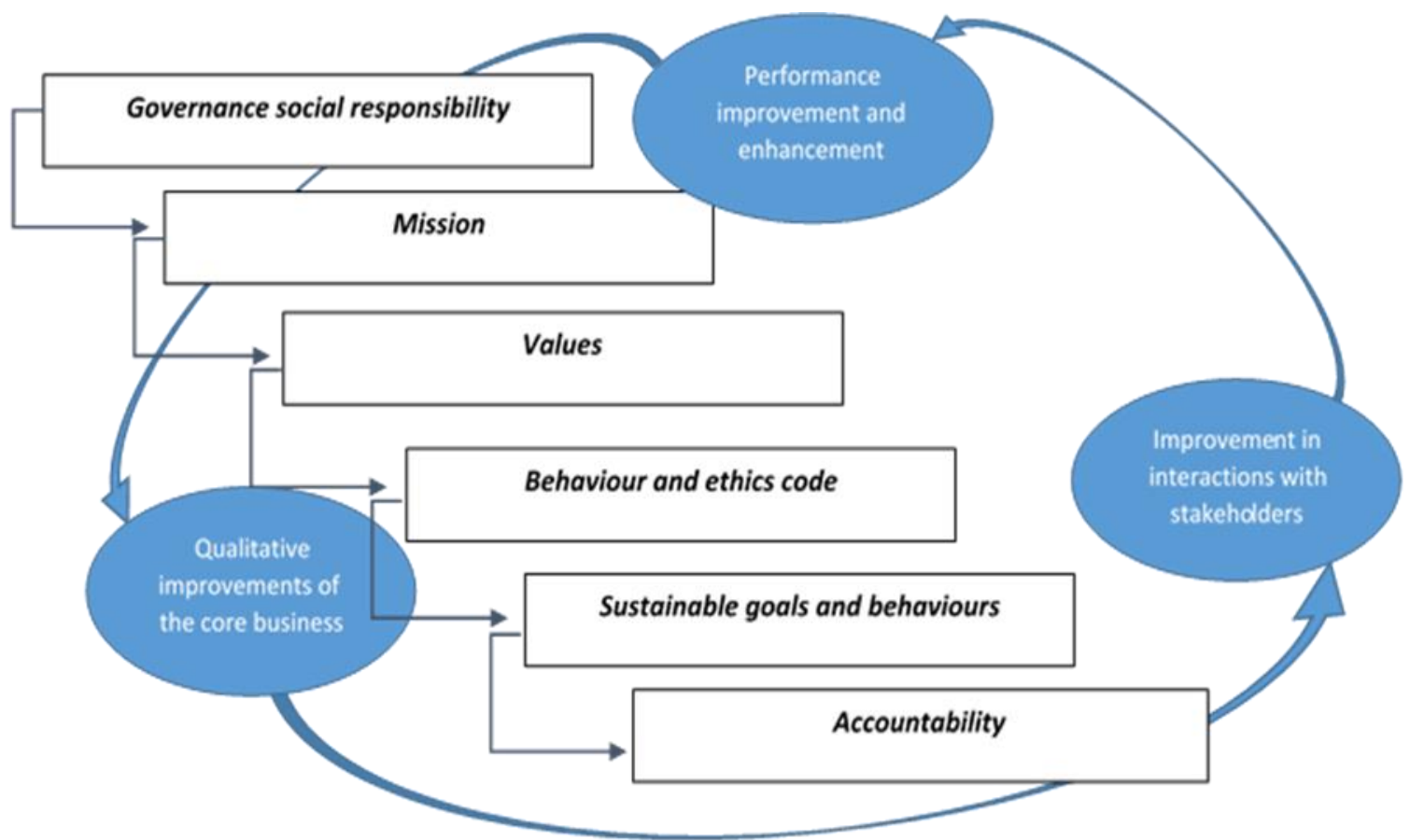

Figure 1. The cycle of performance management of the educational institutions

A socially responsible school assumes behaviors that seek to involve stakeholders to better understand their expectations and priorities and transfer these into defining the strategy and goals, into monitoring the objectives in view of promoting the activities and accountability [Gray, 1993; Uitto \& Saloranta, 2017]. Consequently, social responsibility and sustainability are associated with transparency, reputation, consensus and effective monitoring of results, ensuring continuous quality improvements in the core business of the schools.

\section{Network Governance to Improve Performance Management of the Schools}

Sustainability is a condition that defines the quality of the relations between stakeholders and the schools. The quality of relations is reflected in the ability adequately meet educational expectations and scientific advancement, to guarantee employment, contribute to the economic and social wellbeing of a country. An essential role in this direction, is determined by the institutional communication oriented at the sustainability. In this sense, we consider the Sustainability Report the most effective instrument of accountability [Global Reporting Initiative (GRI)] for school system as it can combine schools autonomy and responsibility and increase the evaluation culture in schools, tracing the measurement cycle of school performance. 
With this regard, it is pointed out that the traditional institutional communication of the schools has been insufficient and inefficient concerning transparency and information completeness. The introduction of mechanisms of accountability, oriented to sustainability in schools, if properly structured and correctly managed, leads to improvements in: strengthening the link between statements of mission and adopted strategies; involvement of the social partners; appreciation of the results; point out the "added value" brought by the school.

Educational institutions play a crucial role in the development of economic systems based on disseminating knowledge and innovation, promoting a more resource-efficient economy, greater environmental friendliness and competitiveness to foster cultural growth and social and territorial cohesion. At present, the investment in human capital represents a decisive factor for the sustainability and global and future countries productivity.

In this regard, we can observe that in business economics' literature there are several models well-known among which there are those that have had more success in the school system [Bradely, Crounchely, Millington \& Taylor, 2000 ; ].

The Network Governance model relationship management is the method of development of the aims of this study. Network is intended as a non-hierarchic structure of interrelated elements, where information flows easily and rapidly. The network implies a huge cultural change at first and then an organizational one [Albareda \& Waddock, 2016]. It is a managerial approach which fosters the enhancement of human resources, considered crucial in organizations, the empowerment and the stakeholders' equity of treatment. This is a vision, more and more credited, that sees organizations not only in their structural dimensions as a set of financial and technological resources aimed at developing a mission but also as a set of immaterial resources. In schools, literature and common language, the term network is used to distinguish different situations. Networks are associations among schools but also partnerships that they stipulate with local public institutions. The network can be founded on temporary links, formed around a specific project and for a limited period or it can assume greater stability and be enlarged to different purposes acting on an indefinite period of time.

For this reason social experimentations are ever more frequent and they prefer mechanisms of governance aiming at creating "network agreements" between institutions and stakeholders [Hastings \& Chapman, 2009; Brondoni, 2015; Kerr \& Dyson, 2016].

Networks are based on the belief that public educational services work better if they are designed and implemented in collaboration with other subjects involved (citizens, companies, civil society organizations, etc.) in order to obtain their approval, energy, experience, culture and ambitions [Cullen-Lester, Woehler \& Willburn, 2016]. The networks where schools are involved can operate at different levels and with different aims:

- on a basic level, the network can be carried out to facilitate the sharing of professional best practices among teachers;

- on a more ambitious level of cooperation, the network can involve groups of teachers and schools which work together with the explicit purpose of improving teaching and organizational conditions;

- on a territorial and national level, the network can link different groups of stakeholders to implement policy specifications;

- network agreements, when multiple groups of networks, belonging or not to the educational sector, work together for systems improvement in terms of social justice, inclusiveness, sustainability.

Co-planning and co-production of educational services transform the relations among their end users (students and families) and suppliers (first of all directors and teachers, but also people responsible for policy and other institutions who collaborated with schools), fostering the exchange of competences and experiences and facilitating "the spirit of an authentic partnership to work for common educational objectives" [UNESCO, 2008]. Some studies underlined the positive relation between students' learning outcomes and the school atmosphere characterized by interaction and collaboration among members [Gordon, Young \& Kalianov, 2001; Price, 2005; Stubbs \& Cocklin, 2008].

\section{Conclusion}

The increasing importance to build a learning community and the developments in digital technology force the school to take a proactive approach, strongly oriented towards stakeholder engagement. The proactive approach is significantly influenced by the adoption of policies that emphasise the principles of global responsibility, positive and equal interaction with stakeholders and accountability.

Furthermore, the diffusion of knowledge enables the stakeholders to be better informed and to evaluate or compare the information available. 
Managing stakeholder relationships is an intrinsic component and strategic driver for school governance. To emphasize the role of the stakeholders, the school should map the most significant ones and identify their expectations in line with the concept of triple bottom line (i.e., integration of economic, social and environmental concerns); then, it should select strategic objectives and prioritize them according to the expectations it wants to satisfy firstly, through a globally responsible conduct. Moreover, the school should apply the best mechanisms of governance to spread the culture of responsibility all over their organization. Finally, the school should introduce a plan of internal and external communication towards all the stakeholders, in order to meet their information needs.

The learning community, as a type of network agreement, does not only facilitate the sharing of knowledge but it increases the potential creation of new learning methods which can be used for the benefit of the community as a whole and/or together with its members singularly. This approach is at the basis of the operation of a Participated Network in which the mutual continuous exchange of information, experience, professionalism and performance represents the driving force of growth paths of the whole school system, personal development and rationalization in the use of public resources.

Educational system show a progressive sensibility increase for networks creation and reporting, both according to the need of improving the educational quality and the positive interaction with environment and according to the progressive attention of families and institutions towards the school system. In addition, schools are required to implement, in a relatively short time, the recent regulatory legislations, which emphasize the school communication.

The growing importance of sustainability in corporate governance involves a greater attention to the principles and values of the dominant internal and external relations, innovation, internal processes of behavioral orientation and external communication. In particular, the enhancement of transparency requirements and the multidimensionality of responsibilities, the objectives and the relevant results recommend the adoption of a sustainable accountability system.

In particular, the relationship between expectations, performances and acclaims along the "triple bottom line", highlights the importance of preparation and disclosure of Sustainability Report. With this form of reporting the educational system can: on the one hand, put in evidence the responsible commitments undertaken by school with the goal of autonomy; on the other hand, provide a useful reference for the realization of the processes of evaluation and school self-evaluation, in line with the issues and objectives of the management cycle of public performance.

The divulgation of an effective sustainability report to support a proactive stakeholder engagement, allows to value scholastic performance. In particular, it highlights the social impact, through the highlight of the "school social report"; the economic impact, by measuring added value created and distributed by school; the environmental impact, through the analysis of the sustainable activities implemented by the school.

The contribution given by the compulsory school in favour of a smart, sustainable, inclusive growth, leads to reflect on the incompleteness of an accountability model only focused on social dimension, given the close interrelationship between social function and ability of effective and efficient use of limited available financial resources.

In this sense, the sustainability report represents the most effective instrument of accountability for school system as it can:

- combine schools autonomy and responsibility;

- increase the evaluation culture in schools, tracing the measurement cycle of school performance.

At a glance we think that thanks to the adoption of accountability models inspired to build a network governance of mutual data exchange, it's possible to positively feed an effective performance management finalized to highlight a clean and fair management of public funds. By acting with integrity and transparence the schools positively affirm their image and reputation, builds consensus and trust.

\section{References}

Albareda, L., \& Waddock, S. (2016). Networked CSR Governance: A Whole Network Approach to Meta-Governance. Business \& Society, 1-40.

Boeve-De-Pauw, J., Gericke, N., Olsson, D., \& Berglund, T. (2015). The Effectiveness of Education for Sustainable Development. Sustainability, 7. https://doi.org/10.3390/su71115693

Bradely, S., Crounchely, R., Millington J., \& Taylor, J. (2000). Testing for quasi-markets Forces in secondary education. Oxford Bulletin of Economic and Statics, 62(3).

Brondoni, S. M. (2015). Global Networks, Outside-In Capabilities and Smart Innovation. Symphonya. Emerging 
Issues Management, 1, 6-21.

Burton, B. K., \& Dunn, C. P. (2005). The caring approach and social issues in management education. Journal of Management Education, 29(3).

Cassano, R. (2013). Accountability e stakeholder relationship nelle aziende pubbliche. FrancoAngeli, Milano, Italy.

Crow, M. (2010). Organizing teaching and research to address the grand challenges of sustainable development, Bioscience, 60(7), 488-489. https://doi.org/10.1525/bio.2010.60.7.2

Cullen-Lester, K. L., Woehler, M. L., \& Willburn, P. (2016). Network-Based Leadership Development: A Guiding Framework and Resources for Management Educators. Journal of Management Education, 40(3), 321-358.

Folke, C., Carpenter, S., Elmqvist, T., Gunderson, L., Holling, C. S., \& Walker, B. (2002). Resilience and Sustainable Development: Building Adaptive Capacity in a World of Transformations. Ambio, 31(5), 437-440, https://doi.org/10.1579/0044-7447-31.5.437

Franzoni, S., \& Gennari, F. (2013). School Governance: An International Comparison. US-China Education Review, 3(10), 772-779.

Franzoni, S., \& Gennari, F. (2013). School Networks and Sustainable Development. Symphonya. Emerging Issues Management, 2, 32-46.

Global Reporting Initiative (GRI). Sustainability Reporting Guidelines. G3.1 and G4.

Gordon, T. W., Young, J. C., \& Kalianov, C. J. (2001). Connecting the freshman year experience through learning communities: practical implications for academic and student affairs units. College Student Affairs Journal, 20, 37-47.

Gray, R. H. (1993). Current practice in environmental reporting, Social and environmental accounting, 13(1), 6-8.

Hastings, M., \& Chapman, C. (2009). Leading school-based networks. Routledge.

Kerr, K., \& Dyson, A. (2016). Networked Social Enterprises: A New Model of Community Schooling for Disadvantaged Neighborhoods Facing Challenging Times. Educational Sciences, 6, 20.

Mitchell, R. K., Van Buren, H. J., Greenwood, M., \& Freeman, R. E. (2015). Stakeholder Inclusion and Accounting for Stakeholders. Journal of Management Studies, 52(7), 851-877.

Paletta, A. (2007). Il bilancio sociale nella scuola dell'autonomia. Il bilancio sociale su base territoriale. ISEDI. Torino.

Price, D. V. (2005). Learning communities and student success in post secondary education. MDRC Publications, New York.

Rowe, D. (2007). Education for a sustainable future, Science, 317(5836), 323-324.

Salvioni, D. M. (2005). Corporate governance, management control and global competition. Symphonya. Emerging Issues Management, 1, 39-51.

Salvioni, D. M., \& Astori, R. (2013). Sustainable Development and Global Responsibility in Corporate Governance. Symphonya. Emerging Issues Management, 1, 1-25. https://doi.org/10.4468/2013.1.03salvioni

Salvioni, D. M., \& Cassano, R. (2015). Improvement of management performance in the school system. Conference: The 3rd Virtual Multidisciplinary Conference - Quaesti.com. Publisher: EDIS - Publishing Institution of the University of Zilina, 3(1), 108-112. https://doi.org/10.18638/quaesti.2015.3.1

Salvioni, D. M., Astori, R., \& Cassano, R. (2014). Corporate sustainability and ethical codes effectiveness, Journal of Modern Accounting and Auditing, 10(9), 969-982.

Salvioni, D. M., Gandini, G., Franzoni, S., \& Gennari F. (2012). The role of key actors in school governance: an italian evidence. US-China Education Review. B, Education Theory, 2, 881-897.

Stubbs, W., \& Cocklin, C. (2008).Teaching sustainability to business students: shifting mindsets. International Journal of Sustainability in Higher Education, 9(3), 206-221.

Uitto, A., \& Saloranta, S. (2017). Subject Teachers as Educators for Sustainability: A Survey Study. Educational Sciences, 7(1), 8. https://doi.org/10.3390/educsci7010008.

UNESCO, (2008). A framework for action on education governance (Only Italian version). 